\title{
Transactional Analysis as a Method to Test the Quality of Life of a Family
}

\begin{abstract}
One of the actions that affect the quality of life of the family as a complex system of relationships is interpersonal communication that takes place between the members of the family. In line with the transactional analysis, the trend in psychology founded by E. Berne, relationships between individuals should be based on honest and open disclosure of one's desires and attitudes, i.e. variety of transactions. Otherwise, there are specific game leading to maintain and increase the distance between family members, weaken the ties between them and leading to a reduction in the quality of interpersonal relationships.

The paper below aims to make closer the problems of transactional analysis, beginning from the explanation of the structure of "Ego" according to Berne and the terms "transactions", "reinforcement" and "life scripts". There will be presented also games played in family environment and their consequences for the proper functioning of the family.
\end{abstract}

Key words: interpersonal communication, communication in the family, transactional analysis, Berne, family games.

Transactional Analysis is one of theory of contemporary psychology that has been widely popularized. It is used in considering of development of individuals according to the experiences from childhood and the quality of relationships with significant people. Berne noticed that this is verbal communication, especially that which occurs directly between two people, which is the center of interpersonal relationships and affect their quality both: improving and disturbing them. The key point to understand the idea of transactional analysis as a way of considering the system of relationships among the members of a family that affects the quality 
of its functioning, is the Ego-state. It is important in what way we establish relationships with other people (transactions), what roles we take, what kind of support we give to our closest (strokes), if we impose to ourselves the way of acting in adult life (life scripts). All factors that are presented below may lead individual to get involved in games to avoid intimacy in relationships and to deterioration of interpersonal relationships in the family.

\section{Ego-state}

Transaction analysis assumes the existence of three complimentary states of Ego: (Parent, Adult, Child) that creates specific way of feeling and behaving and expressed by specific behaviors of a verbal and non-verbal kind.

Illustration 1. Ego-states in transacional analysis

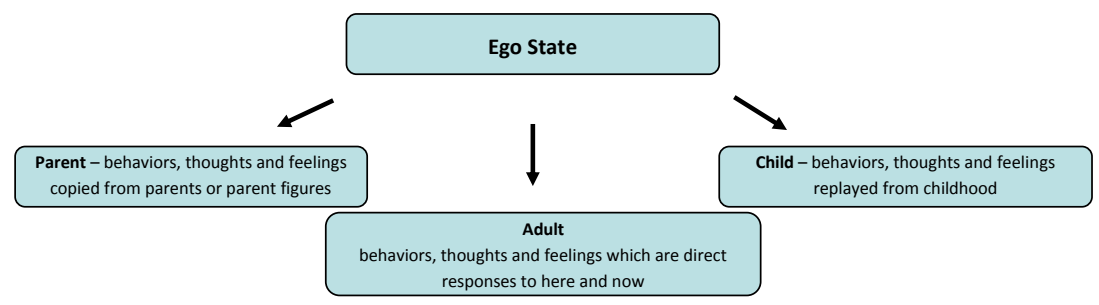

Source: http://www.businessballs.com/transactionalanalysis.htm.

Ego-Parent - the structure that includes experiences of individuals connected with their growing up by parents or other important people. It consists of beliefs of what one should behave in a society, what is right or wrong and decides how people should live like. It can take two forms: Critical Parent, who focuses on oppressions and suppressions and strictly abide regulations, and Supporting Parent, who offers unconditional love and safety. Parent does many reactions automatically what saves a lot of time and energy.

Ego-Adult - is based on information derived from the surrounding world, processes them using logical thinking and uses for a more adequate social functioning of individuals. It is the most 'rational' of the Ego - states that takes control over two others, focused on effective functioning of individuals, directing to meeting the targets. Adult is often identified with Ego-Ideal. Adult is well organized, elastic, intelligent and his way of functioning is to analyze reality, estimate the probability and process the data in neutral way.

Ego-Child - this is the part of personality focused on feelings. It is often regarded as a cause of troubles of individuals because of egocentrism, emotionality and persistence in subjecting the changes inevitably associated with growing up. It can take three forms: Natural Child (spontaneous, open to experience and 
susceptible to injury), Little Professor (interested in world, creative and based on imagination) and Adapted Child (trying to adapt to the world around or rebellious against the imposed restrictions, which may cause feelings of fear or shame). The child is in many ways the most valuable part of the personality and can make the life of the individual exactly what a real child brings to family life: grace, joy and creativity [Berne 1994; Jagieła 2006; Jagieła 2001; www.changingminds.org].

Each of Ego-state can be distinguished by an observer on the basis of specific indicators both of verbal and non-verbal nature. Beginning with Parent, who most common uses body language that shows impatience or anger, pointing by fingers person or things, showing patronizing gestures. Most common uses words: "always", "never", "once and for all", criticizes, judges. Adult shows in non-verbal way the interest of the interlocutor by leaning in his direction, doesn't feel insecure and doesn't threat others. Asks questions with phrases: "why", "what", "who", "I think that...", "I understand...". The fact that interlocutor is in the Child State can be derived from his behavior full of emotions - sadness, despair, joy, what he shows to incidental viewers through non-verbal messages such as shaking shoulders, smiles, daydreaming sight or tears. The person uses abbreviations, wants to give an impression, says: "I want", "I demand", "I don't care", "The worst day of my life", etc. (http://www.businessballs.com/ transactionalanalysis.htm).

\section{Transactions}

Transactions are every exchange done between two people that can take the form of messages both of verbal and non-verbal nature. They are consists of stimulus and reaction that take place between two Ego-States. The person who answers the transactional stimulus can derive it from any Ego-State [Rogoll 1994]. Thus we can say about nine possible channels between the participants of interaction. It is assumed that there are transactions: complementary and crossed, reciprocal and ulterior. In case of ulterior transactions there can be two options: angular and duplex.

In the right model of interpersonal communications the transactions are established between the two corresponding Ego-States - this situation is described as complementary transactions. The most valuable transactions are between two Adult-States of both participants. The transactions between Parents and children are also right. 
Illustration 2. Complementary transactions
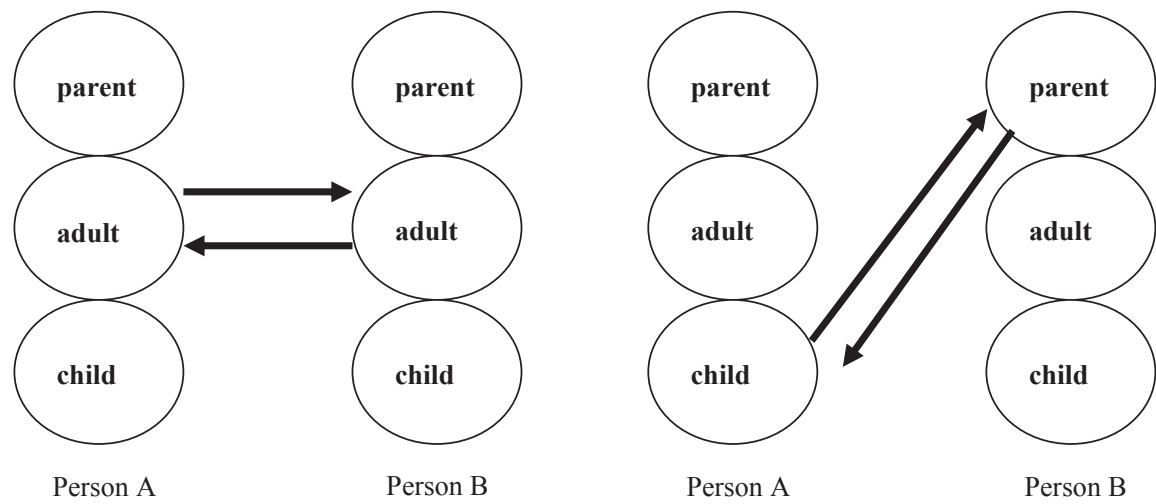

Source: Berne 1994, p. 22.

In the situation, when the message is addressed for other than initial EgoState, the crossing transaction occurs that causes interruptions of the process of interpersonal relation. They can be observed when long talks between individuals are finished with phrases as: "What is really your point?", "I told you that many times", "there's no way to talk to you". As it was noted by Rogoll "partners are talking not to each other but next to each other" [Rogoll 1989, p. 39]. The reason of such state is focused only on oneself and treating the interlocutor as someone of less value or threating. The worst situation from the point of view of functioning of the family is to regard the partner of interaction as a scapegoat who can be the objective of all negative emotions arisen on the basis of the feeling of selfimperfection. These relationships can take place on the occasion of marital dyad as well as between parents and their children, especially when the children don't want to implement unrealized life-scripts of their parents, or they turn out to be better than the parents in some spheres of life (what is the cause of frustration or envy of parents if they are unable to act as an autonomous individuals fully appreciating the achievements of their offspring).

The most important communication problems from the perspective of the games theory, occur when the individual establishes the ulterior transaction - the messages have the different content that this from the intentions of the sender (he or she says something different that matters). These messages go on two levels: social-open (Adult-Adult) and psychological-hidden (Child-Child or Adult-Child). The featured angular transactions take place among three EgoStates, while duplex transactions involve four Ego-States. Because of domination of the Child-State in the structure of every personality, the most often result of the ulterior transaction determines the whole result of the interaction undertaken [Berne 1994; Rogoll 1989]. 


\section{Illustration 3. Crossed transactions}
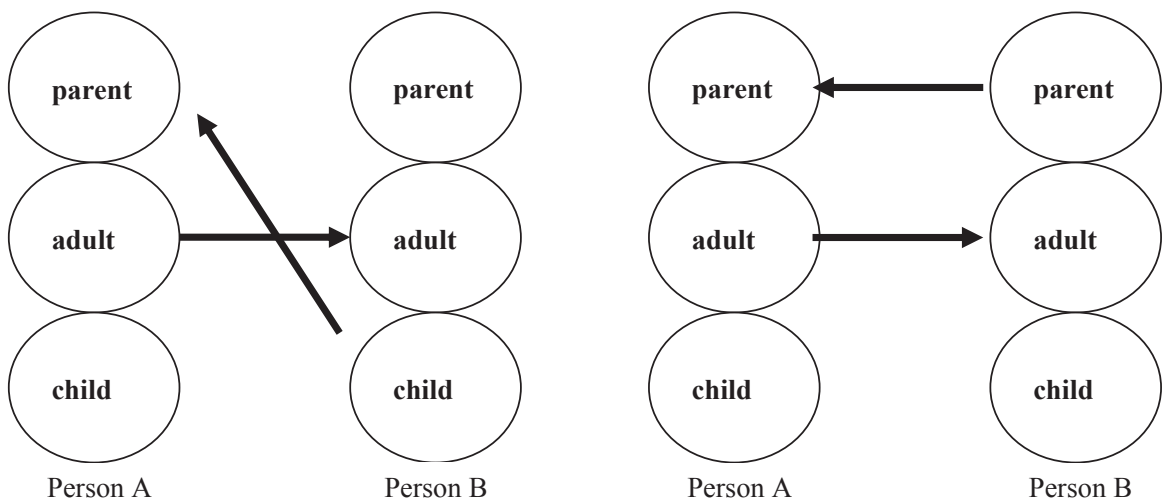

Source: Berne 1994, p. 22.

Illustration 4. Ulterior transaction (angular and duplex)
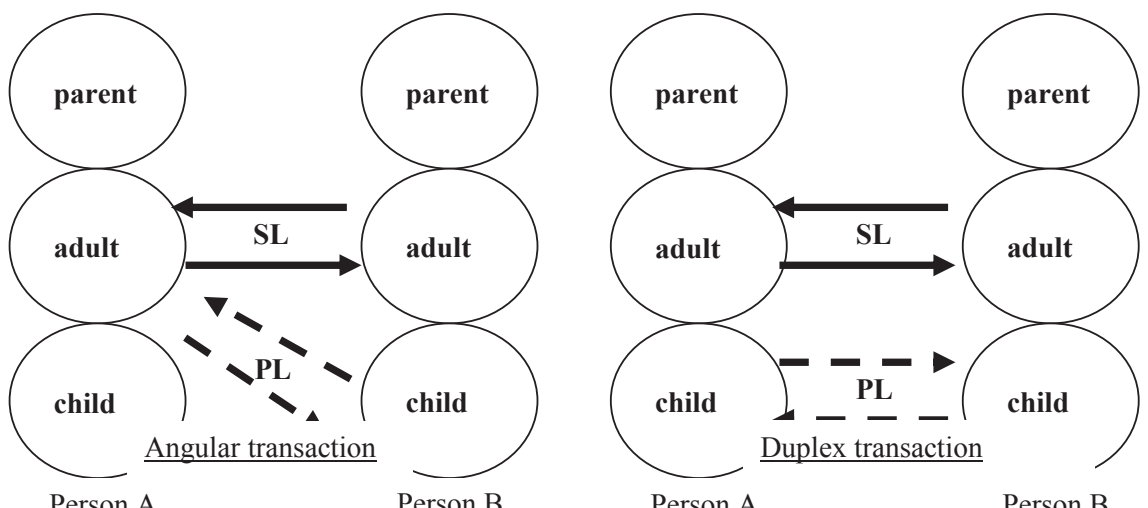

SL - social level; PL - psychological level

Source: Berne 1994, p. 25.

\section{Support (strokes)}

In addition to the quality of interaction based on communicating an important role in the selection and duplication with the games in the family is the ability of family members to provide support to its partners (strokes) both: positive and negative [Rogoll 1989]. Positive support (You are OK) let us meet such crucial for proper functioning needs as: need for safety, recognition or selfesteem, what leads to enrich interpersonal relationships occurring in the family and prevents from dysfunctional behaviors such as: intergenerational conflicts, 
addictions or even breakup of marriage. Unfortunately more often there can be met negative support (You are not OK), done by reducing self-esteem of close relations, punishing (parents-children) or disregarding rules (children-parents). From the point of view of proper qualitative functioning of the family the worst situation is when negative support occurs not as an reaction for objective stimulus (e.g. spouse is late for an important meeting or another bad mark of the child at school), but as a way to discharge bad mood, that means when we - the senders of the message with negative support, we feel "not OK". On the other hand through reprimands and lack of positive support we demonstrate with a little effort our power over partners of interaction. In the family environment there's often a specific chain of negative support between individuals, on the level of adults (spouses, grandparents), children, and between levels (a son scolded by a father who is tired after work, will take a revenge on younger brother, who will destroy favorite mug of his mother and she will react on her husband etc.)

There are two kinds of positive support that are worth to be distinguished: unconditional and conditional. The last one is a kind of a manipulation of the partner of interaction, it forces real favors (If you do your homework..., if you dispose the garbage...) or emotional (If you go with me to my aunt's party, If you agree to go for a holiday where I want to go...) in exchange for our sympathy (... than I will love you, respect you and appreciate). If bringing the children up is based on conditional support, it became the effective method leads to teach them the life script saying that there's nothing for free in life, that every positive feeling must be deserved. Further consequences of that is that individuals is convinced about its low self -esteem and may lead to a loss of dignity and to attitude of learned helplessness. Thus it affects not only the quality of the present family, but it also, in potential way, disrupts the relationships that may be established in future and may make impossible to create a mature relationship based on partnership (the "I am not OK" attitude).

Prospects for development of an autonomous personality gives the use of positive reinforcement in the family of an unconditional nature. In this case we do not expect from our partners or children anything for giving love to them. This behavior leads to enforce the belief in individual about its uniqueness, allows to create the right picture of oneself and to live with the attitude „I am OK”.

According to the fact that the individual needs acceptance for effective and healthy functioning, it will seek for the acceptance with methods derived from childhood. People who are accepted, perceiving others as equal to themselves will exchange between themselves the positive support; but persons who are not feel like OK, will show tendencies to neglect others and to give negative support. The most desperate way of drawing attention is to undertake some psychological maneuvers, from which the most interesting are the games drawn from the ulterior 
transactions. The aim of the games is to avoid intimacy (warmth, emotional closeness), based on honest and direct interpersonal relationships. People who prefer games cannot or do not want to undertake activities to increase empathy, love, spontaneity, and naturalness in relationships. What becomes safe for them is superficial, often hurtful, decreasing the warmth and closeness relationships using surrogate feelings (feelings somehow revealed as a substitute for the real feelings that showing is punished by the environment) [Rogoll 1989]. The ability to experience real feelings in the Ego structure has the Natural Child, while Adapted Child experiences surrogate feeling (e.g. Child that learned that it is not allowed to show anxiety or fear and what is social accepted is positive feelings only - „Boys don't cry”).

\section{Drama Triangle}

Destructive, decreasing the value of the unit or its partners, substitute feelings impact is reflected in the adoption by them, one of the three roles so called Drama Triangle appears in each trading game. We can play as Victim, Rescuer or Persecutor [Karpman 2005; Suchańska 1993].

Victim is a person that regards him or herself as being of less value, more stupid, let others being better, more talented, more clever. With own behavior provokes to be helped (Rescuer) or to be criticized (Persecutor). The repetition of such a schema can suggest that the person took a life script ("I am so poor") that allow to release from decision making, problem solving and be happy [Karpman 2005]. The individual that takes the role of Helper/Rescuer are in interpersonal relationships according to the phrase: „Let mi help you/let yourself to be helped by me". He or she undertakes the reactions that lead to make the feeling of the Victim better, and thus making the Victim addicted to him or her. Helping is not in this case unselfish activity but brings to the Rescuer feeling of domination and superiority over the Victim. The role of Persecutor is connected with the occurrence from the position of power and leads to the proof of thesis that "it is all your fault". Being in this role is connected with using other restrictions, oppressions, threats, insults, humiliation in relationship. It is revealed by anger caused by reactions of others or situations made by others [Karpman 2005].

In interpersonal relationships, even those taking place in families, involvement in Drama Triangle, connected with support each other basing on substitute feelings is engaging to such extend that it is preferred not to search for more satisfying and improving quality relations but to keep in this scheme with frequent role exchanging [Rogoll 1989; Steiner 2000].

The family is a kind of "testing ground" to be learned by children function in one of the above roles. Most often because of their age and lack of life experience, they begin their education on the role of Victims, who are prevented 
from the enjoyment of the sensory experience or expression of joy. In the case of dysfunctional families, e.g. with alcohol problems of a parent, they are assigned the role of the rescuer, who, in time, can transform into role of Persecutors, recognizing their superiority over the addicted parent who is in a role of a Victim.

It seems that the only effective way to avoid the Drama Triangle in the family is to undertake by all members try to stay in Adult-State and not to allow to be provoked to play the role of Victim, Rescuer or Persecutor.

\section{Life scripts}

Transactional analysis assumes that most of people are doing according to the slogan: "I am OK". People who consciously seek for autonomy can and want to establish their life-plan on their own, according to their real personal features and needs. They can be aware of their own abilities and reject all what make them to live in any limitations made by something or someone. However, more than once the decisions made in childhood by parents or other important people create specific scenario that leads the decisions of individuals in their adult life. This scenario may define the norms of behavior or ways of ending life, as well as may be the preferred set of moral rules or definitions concerning the activities of the individuals in the field of interpersonal or professional relationships [Grzesiuk 1994; Porpiglia 2004; Steiner 2000].

In a situation where a child is brought up by parents and relatives granting him unconditional, positive support it is most likely to create a mature personality structure, with mutually complementary ego states. However, in many families, there is a model to guide the life of the child using the do's and don'ts, often without taking into account the potential of developing a young individual. The prevailing attitude is expressed in the so-called raw commands (injunctions), rigidly define his or her life script.

Depending on their content and consequences of using for quality of family or personal life, the life scripts can be divided into three categories: wining, loosing or trivial.

Winning scripts assume having clear aim of life and make individual functioning easier in interpersonal relationships and social environment. They are characteristic for people with attitude "I am OK, you are OK". They consist of life models: "You are perfect", that assumes the striving for perfection in personal and professional life; "You are strong" that shows in ability for taking control over the situation (sometimes to the detriment of emotional life); "Take the challenges" that are characteristic for people that boldly take new projects and take challenges of professional and personal nature.

Loosing scripts as an opposite of winning scripts are the excuse for failures that the individuals meet during development. There can be some examples of these: 
"You never succeed", "You're gonna achieve nothing", "You are the same looser as your father is". They are excellent food for people with learned helplessness derived from being bringing up this way. They are typical for individuals with attitude: "I am not OK, you are not OK" and "I am OK, you are not OK".

Trivial (non-winning) scripts are typical for individuals taught the attitude "I am not OK, you are OK". They are leading neither the situation of fully managing with one own life, nor to assume that there is going to be inevitable failure. They direct life of people who cannot or don't like to make any challenges and value life without ups and downs. They are consists e.g. of model: "I don't like any difficulties" [Grzesiuk 1994; Porpiglia 2004; Sasak 2006].

\section{Games}

In the transactional analysis games are the elements bringing together Ego-structure, transactions, strokes, scripts in one pattern of behavior that is undertaken by "players" in view of effect expected. They aim to manipulate the partner of interaction, they are so called "interactions with hidden trap" [Grzesiuk 1994, p. 70]. Although at the social level they are correct, they are unfair on a psychological level (cf. ulterior transactions). Although they may differ in the length and intensity are always performed without Adult. They are uundertaken for many reasons, from which the most important are: structuring the time, gaining strokes with blocking intimacy and keeping the distance, keeping the substitute feelings, confirmation of parental prohibitions, and thus imposed life scripts, keeping the attitude "You are not OK" and having sense of others being predictable [Rogoll 1989; www.businessballs.com].

The overall division of games assumes distinguishing according to the purpose of their undertaking. The most important for development of the individual and in the meanwhile the most associated with quality of living in family environment are games connected with identity of the individual, authority and avoidance.

Games associated with identity problems can be undertaken because of necessity of drawing an attention. Because people like to be appreciated by an environment, what helps them to develop their sense of individuality and uniqueness, so they seek to be highlighted and appreciate by others. If they cannot do this by positive behaviors, they often act with no accordance to the norms that obey in the family, e.g.: children behave bad, they avoid school, they identify themselves with criminal groups, parents become workaholic or lead to break the marriage. In order to draw an attention, one of the members of the family can fall ill chronically (psychosomatic illness) or only pretend to feel worse. It is often that the school phobia that the child has is the cause of Drama Triangle. Other cause of undertaking identity games is the desire to draw someone sympathy, for example by acting leading to empathy or sympathy among other members of the 
family ("I will help you mum/dad", "Let me darling do the housework for you"), behind this there's desire to draw someone's favors and use them in the future.

Another purpose of undertaking games is to take the control over the environment, often in order to prevent from fear or feeling unsecure. Social capital manifests itself in an attempt to maintain a balance between the favors which do yourself in relationships with other people. Taking the authority can be by suggesting that the partner owes us more and thus something should be done for us. Some of the games are based on taking the power, sometimes by any possible means, not always acceptable. The desire to take the control can also lead to games based on the desire to take the revenge or punish the Victim for sins against Persecutor.

The last category of games is connected with avoidance of behaviors that requires taking the responsibility. There can be observed here an escape - allowing to avoid contact with issues or people that can hurt the individual, excuse - made to dump the blame for failures to others, what allows to duplicate inadequate patterns without any consequences, and transfer, when for example the cause of marriage problems is put in unsuccessful career [www.changingminds.org].

\section{Family games}

Here are presented the most common family games, both these taken only by spouses as well as these that affect also children.

See What You Made Me Do (SWYMD)

It includes two people: Victim and Prosecutor. Its thesis is to dump responsibility for what one did to another person (What I have done is your fault, I am innocent). It can manifest in forcing the Victim to undertake some missions that are in advanced doomed to fail or in asking about the procedure in specific situations - if the procedure proposed fails, the Prosecutor is innocent as he was only acting according to the procedure proposed by the Victim. It is one of the games easily taken by children [Berne 1994; Dawntreader 1996; www. changingminds.org].

\section{Courtroom}

It includes usually three people (e.g. parent and two children or parents and a child). The starting point is tendency of the Prosecutor to be admitted right, no matter the objective reality is. The prosecutor forces to make an opinion in accordance with his/her opinion by using messages as: "She (the Victim) says that it was in such a way, but I will tell you how it was really". In the meantime towards the Victim the phrases are formulated: "All agree with me that..." [Berne 1989; Dawntreader 1996].

\section{Why Don't You - Yes But (YDYB)}

It is the game in which the initiative person (the Victim) wants the Child to be calm down and to drive an attention by ostentatious searching for a solution of 
the problem (usually imagined) by the adult partner of interaction (the Rescuer). Every suggestion ("why don't you do it this way") is rejected by the Victim ("yes, but...”). The game plays until the Rescuers are out of solutions, or until the Victim will be attacked for his hesitation. On the other hand, the Rescuer can play the game I'm Only Trying to Help You that leads to proving the prevail of the Parent over the Child that needs help [Rogoll 1994, Dawntreader 1996].

\section{Uproar}

This is a game full of emotions, played generally between people being in long term relationships. It brings together individuals who know very well "the weakest link" of other player. It is often refers to personal attack either on the players, or their parents or relatives [Dawntreader 1996].

\section{Corner}

Can be played between adults as a dishonest refusal of taking the other's game for example by changing the subject of the conversation. In families it is often between parents and children, and refers to situation in which every activity taken by a child is incorrect. [Berne 1989].

Wooden leg

Is a game often undertaken by children wishing to get rid of the responsibility for their actions. It is based on the thesis: „What can you expect from someone who has a wooden leg?", that means that someone is handicapped no matter: in real life or in fantasy, or needs support. It allows to hide weaknesses that are simulated and to discourage to give positive reinforcements. [Berne 1989, Dawntreader 1996].

\section{Recapitulation}

Transactional analysis, however, at the beginning was only for assessment of communication processes between individuals, turned out to be an effective way to evaluate of functioning of the complex system of family. Thanks to the observations of relations that take place in the family and dependences, such as: exchange of support (positive, negative, conditional or unconditional), messages, making life scripts, or playing games, the level of satisfaction, openness or quality of relationships can be easily defined. Moreover, parents and grandparents are the first teachers of specific life attitudes (connecting with being or not OK), or shape the views regarding life scripts. It seems that the most important thing to autonomous development of individual that comes out of home should be the premise of possibility of achievement true intimacy and warmth in interpersonal relationship without the necessity to reaching the goals with using games. 


\section{Bibliography}

Berne E. (1994), W co graja ludzie, Warszawa, PWN.

Dawntreader C. (1996), Of Frogs and Princes, www.frogsandprinces.dawntreader.net, access 4.11.2014.

Grzesiuk L. (red.) (1994), Psychoterapia, Warszawa, PWN.

Jagieła J. (2006), Nauczyciele i rodz̨ice, czyli gracze i przegrani, „Charaktery”, 2.

Jagieła J. (2001), Psychomanipulacja w sektach w świetle analizy transakcyjnej, www. sekty.sluzew.dominikanie.pl, access 4.11.2014.

Karpman S. (2005), The Drama Triangle, www.mental-health-today.com, access 4.11.2014.

Porpiglia T. (2004), What is a Life Script, http://www.frontiernet.net/ lscriptc/ls1.htm, access 4.11.2014.

Rogoll R. (1989), Aby być sobq. Wprowadzenie do analizy transakcyjnej, Warszawa, PWN.

Sasak T. (2006), Model rozwoju osobistego w analizie transakcyjnej (wg E.Berne), www. NowoczesnaFirma, WP.PL, access 4.11.2014.

Steiner C. (2000), A Compilation of Core Concepts, www.claudesteiner.com, access 4.11.2014.

Suchańska A. (1993), Trójkąt dramatyczny i gry ratownicze [w:] J. Santorski (red.), ABC psychologicznej pomocy, Warszawa: Jacek Santorski \& Co.

www.changingminds.org, access 4.11.2014.

http://www.businessballs.com/transactionalanalysis.htm, access 4.11.2014. 